\title{
DisCUSSÕES SOBRE A EDUCAÇÃO INCLUSIVA NOS ESPAÇOS DOS CURSOS DE FORMAÇÃO INICIAL E CONTINUADA DE PROFESSORES
}

\author{
DISCUSSIONS ON INCLUSIVE EDUCATION IN THE SPACES OF INITIAL AND CONTINUING \\ TRAINING COURSES FOR TEACHERS
}

DISCUSIONES SOBRE EDUCACIÓN INCLUSIVA EN EL ESPACIOS DE CURSOS DE FORMACIÓN INICIAL Y CONTINUA PARA PROFESORES

\author{
Jáisse Mendes Souza \\ Cunha \\ (iD) 9 \\ Especialista em Educação, \\ Contemporaneidade e Novas \\ Tecnologias (UNIVASF) \\ Discente da Pós-Graduação Lato \\ Sensu em Docência com Ênfase na \\ Educação Inclusiva (IFMG) \\ Campus Avançado Arcos \\ jaissecf@hotmail.com
}

\section{Luciano da Silva Pereira (iD) 9}

Doutorando em Educação

(UNIRIO)

Professor efetivo na Escola

Estadual Prof ${ }^{\circ}$. Benedito de

Carvalho

Discente no Programa de

Doutorado em Educação

(UNIRIO/PPGedu)

luciano.educmt@gmail.com

\section{Cláudio Alves Pereira \\ (iD) 9}

Doutorando em Educação (UFES)

Professor no Centro de Educação a

Distância do Instituto Federal de

Minas Gerais (IFMG) Campus

Avançado Arcos

Discente no Programa de

Doutorado em Educação (UFES)

claudioapessoal@gmail.com

\begin{abstract}
Resumo
O objetivo do artigo é analisar como a temática em tela se desenvolve nos cursos de formação continuada dos professores em duas cidades brasileiras, Cuiabá, no estado de Mato Grosso e Presidente Dutra, na Bahia, assim como identificar se houve, em sua formação inicial, disciplinas que os preparassem para os processos de educação inclusiva e se, no exercício da docência, tais educadores tiveram oportunidades para formações continuadas na área. A metodologia baseou-se na perspectiva da abordagem qualitativa e o principal instrumento de coleta de informações foi um questionário eletrônico disponibilizado no Google Forms. Teoricamente, o artigo se apoia em Diniz (2012), Duek (2014), Pletsch (2009), entre outros. Os resultados apontam que os professores entrevistados reconhecem a importância de discutir a temática da inclusão no ambiente escolar, seja na formação inicial ou continuada e, da mesma forma, reconhecem que muitas ações por parte dos órgãos competentes têm permanecido presentes apenas nos documentos normativos.
\end{abstract}

Palavras-chave: Educação. Formação. Inclusão. Professores.

Recebido em: 13 de março de 2021.

Aprovado em: 27 de abril de 2021.

Como citar esse artigo (ABNT):

CUNHA, Jáisse Mendes Souza; PEREIRA, Luciano da Silva; PEREIRA, Cláudio Alves. Discussões sobre a educação inclusiva nos espaços dos cursos de formação inicial e continuada de professores. Revista Prática Docente, v. 6, n. 1, e027, 2021.

http://doi.org/10.23926/RPD.2021.v6.n1.e016.id1096 


\section{Abstract}

The objective of the article is to analyze how the theme on screen develops in the continuing education courses for teachers in two Brazilian cities, Cuiabá in the state of Mato Grosso and Presidente Dutra, in Bahia, as well as to identify if in their initial training there were subjects that prepare for inclusive education processes and whether, in the exercise of teaching, these educators had opportunities for continued training in this area. The methodology adopted the perspective of the qualitative approach and the main instrument for collecting information was an electronic questionnaire available on Google Forms. Theoretically, the article is supported by Diniz (2012), Duek (2014), Pletsch (2009), among others. The results show that the teachers interviewed recognize the importance of discussing the theme of inclusion in the school environment, whether in initial or continuing education, as well as, they recognize that many actions by the competent bodies have remained only in the normative documents.

Keywords: Education. Training. Inclusion. Teachers.

\section{Resumen}

El objetivo del artículo es analizar cómo se desarrolla la temática en pantalla en los cursos de educación continua para docentes en dos ciudades brasileñas, Cuiabá en el estado de Mato Grosso y Presidente Dutra, en Bahía, así como identificar si en su formación inicial hubo asignaturas que preparan para procesos de educación inclusiva y si, en el ejercicio de la docencia, estos educadores tuvieron oportunidades de formación continua en este ámbito. La metodología adoptó la perspectiva del enfoque cualitativo y el principal instrumento de recolección de información fue un cuestionario electrónico disponible en Google Forms. Teóricamente, el artículo está respaldado por Diniz (2012), Duek (2014), Pletsch (2009), entre otros. Los resultados muestran que los docentes entrevistados reconocen la importancia de discutir el tema de la inclusión en el ámbito escolar, ya sea en la educación inicial o continua, así como, reconocen que muchas acciones de los órganos competentes se han quedado solo en los documentos normativos.

Palabras clave: Educación. Capacitación. Inclusión. Maestros. 


\section{INTRODUÇÃo}

A educação especial e os processos de inclusão escolar são dois grandes desafios da educação brasileira, tendo em vista que, apesar da Constituição Federal (CF) de 1988 garantir o direito e acesso à educação para todos, a realidade educacional evidenciada é outra. Estudo comandado pelo Instituto Brasileiro de Geografia e Estatística (IBGE), a Pesquisa Nacional por Amostra de Domicílio (PNAD) de 2019 revelou que 12,5\% dos adolescentes, de 11 a 14 anos, e $28,6 \%$ das pessoas, de 15 a 17 anos, ou estavam atrasados ou haviam abandonado o ensino regular. Entre os jovens de 18 a 24 anos, 11,0\% estavam atrasados e 63,5\% não estavam frequentando a escola, sem terem concluído o ensino obrigatório. Esses dados demonstram como permanece grande o número de pessoas excluídas do espaço escolar. Nesse sentido, alguns movimentos sociais e autores (PLETSCH, 2009; DINIZ, 2012; DUEK, 2014; LEITE; MACHADO; SILVA; RIOS, 2019) discutem e trabalham com a educação inclusiva têm alertado que não se pode pensar em uma educação verdadeiramente inclusiva se não revermos como as ações de formação inicial e continuada dos educadores estão ocorrendo.

Assim, este artigo tem como objetivo precípuo analisar como a temática em tela tem sido desenvolvida em ações de formação continuada dos professores em duas cidades brasileiras, Cuiabá, capital do estado de Mato Grosso e Presidente Dutra, localizada no interior da Bahia.

Consideramos que a discussão deste estudo poderá contribuir para ampliar o debate sobre a temática posta em pauta e, conseguinte, propor políticas de formação continuada que contemplem a diversidade intrínseca aos processos pedagógicos presentes no espaço escolar, levando aos gestores da educação a realidade que, muitas vezes, acreditam estar superadas, fato que os levam a reforçar as heranças hegemônicas e eurocêntricas do período colonial. Pensar em educação inclusiva vai além de centralizar o olhar em apenas num determinado grupo social excluído, trata-se de ofertar a todos e a todas uma educação que respeite as diferenças e possibilite a esses sujeitos superarem os desafios impostos pela sociedade. Assim, a unidade escolar precisa problematizar, discutir, refletir e propor mudanças, superando processos e imagens que reforçam a exclusão.

As discussões mais contundentes sobre um ensino inclusivo têm como marco inicial o ano 1994, a partir da Declaração de Salamanca, documento elaborado durante uma convenção da Organização das Nações Unidas (ONU), realizada na Espanha, que contou com a presença de 88 países e 25 representantes de organizações internacionais. Juntos, os países participantes 
(entre eles o Brasil) assumiram o compromisso de (re) construir um novo sistema educacional baseado em princípios inclusivos, com desígnio de garantir a todos os alunos que suas necessidades de aprendizagem fossem atendidas, garantindo o acesso, o ingresso e a permanência total nas fases/modalidades da escolarização (UNESCO, 1994).

Nesse contexto, Pletsch (2009) afirma que a política de educação inclusiva no Brasil deve entrar num debate mais amplo que perpasse os contextos social, político e econômico, permitindo a evidenciação das realidades. Para ela, tais realidades apresentam-se nos documentos normativos que tratam da educação especial - mas os enunciados constantes na Declaração de Salamanca e na CF 1988 não têm ecoado no dia a dia do ambiente escolar.

Nesse contexto, de pensar uma educação que fosse ofertada a todos, o Brasil regulamentou em 1996 a Lei de Diretrizes e Bases da Educação Nacional (LDB), Lei nº. 9.394, sendo esse o maior documento da legislação educacional brasileira. Anteriormente, o Brasil já tinha experimentado as LDBs de 1961, uma alteração promovida nesse texto em 1968 e, posteriormente, a LDB de 1971. É importante destacar que a LDB de 1996 foi a primeira legislação nacional que trouxe um olhar específico para a Educação Especial; anteriormente, a educação especial se apresentava dispersa em outras seções que tratavam da educação nacional. Assim, a partir da Lei $\mathrm{n}^{\circ}$ 9.394/1996, fica determinado que os sistemas de ensino devem promover a educação especial em seus métodos, currículos, práticas e, principalmente, inserir nos cursos de formação inicial e continuada a temática da educação especial de maneira a preparar os professores para atender as necessidades educacionais especiais dos alunos.

Segundo o Ministério da Educação (MEC), as adequações para atender a todos os estudantes, garantindo-lhes o acesso e permanência, "devem ser dadas pelo sistema educacional, de forma a favorecer a todos os alunos e dentre estes, os que apresentam necessidades educacionais especiais, de acesso ao currículo, participação integral, efetiva e bem-sucedida em uma programação escolar tão comum quanto possível” (BRASIL, 2000, p. 7). Nesse sentido, houve um crescente debate no cenário educacional brasileiro para que as unidades de ensino fossem capazes de desenvolver políticas educacionais de inclusão destinadas não apenas a um determinado grupo, mas a toda diversidade presente em seu espaço.

Como pensar no processo de inclusão escolar, se os profissionais em suas formações iniciais não discutiram essa prática? Como desenvolver um processo de inclusão no dia a dia escolar, se o processo de formação continuada dos profissionais em exercício nos estabelecimentos de ensino não reconhece a diversidade étnica e sociocultural, bem como as 
práticas discriminatórias em suas práticas pedagógicas presentes nesses ambientes? Tais perguntas compuseram inúmeros debates educacionais que se sucederam à promulgação da LDB de 1996, como a Conferência Nacional de Educação (CONAE) e a elaboração do Plano Nacional de Educação, dentre outros.

Assim, como resultado das ações de movimentos sociais e institucionais sensíveis à temática, no dia 9 de janeiro de 2001 o Governo Federal aprovou a Lei nº 10.172 instituindo o Plano Nacional da Educação, garantia de uma formação inicial e continuada capaz de contemplar a diversidade e os conhecimentos sobre a inclusão, contendo questões relativas à educação dos alunos portadores de necessidades especiais, temáticas de gênero, étnico-raciais, entre outras, demarcando importantes avanços em relação à formação de professores no Brasil, não apenas em termos de documentos normativos, mas na produção de conhecimento sobre a temática.

Anteriormente, ainda no 2000, o Ministério da Educação elaborou uma proposta de Diretrizes para a Formação de Professores da Educação Básica, tornada Lei no dia 18 de fevereiro de 2002 e publicada a partir da Resolução $n^{\circ} 1$ do Conselho Pleno do Conselho Nacional de Educação (CNE/CP). Importante destacar que a proposta já denunciava esse cenário educacional fragmentado, apontando que a formação, até então desenvolvida na universidade, distanciava-se da realidade que a educação apresentava, pontuando que o professor atuante no século XXI precisaria de permanente formação, para

[...] orientar e mediar o ensino para a aprendizagem dos alunos; responsabilizar-se pelo
sucesso da aprendizagem dos alunos; assumir e saber lidar com a diversidade existente
entre os alunos; incentivar atividades de enriquecimento curricular; elaborar e
executar projetos para desenvolver conteúdos curriculares; utilizar novas
metodologias, estratégias e materiais de apoio; desenvolver hábitos de colaboração e
trabalho em equipe. (BRASIL, 2000, p. 5).

Esses apontamentos já foram apresentados por Márcia Denise Pletsch, em seu artigo $A$ formação de professores para a educação inclusiva: legislação, diretrizes políticas e resultados de pesquisas (2009) no qual é denunciado que a formação de professores no Brasil segue um modelo tradicional e inadequado para pensar em uma educação inclusiva de modo que torna-se necessário propor melhorias na formação de professores, principalmente com um olhar mais inclusivo e capaz de articular ações de formação inicial e continuada com as demandas da realidade escolar na sociedade atual. Portanto, como assevera Pletsch (2009), o desafio é ofertar cursos de formação de professores que possibilitem que esses profissionais sejam capazes de produzir novos conhecimentos e propor atitudes inovadoras, permitindo a 
compreensão da realidade social. Assim, é preciso pensarmos em políticas públicas educacionais voltadas para práticas mais inclusivas, repensando cada momento formativo que se passa na instituição de ensino superior e nas ações de formação continuada que ocorrem no "chão da escola", no cotidiano escolar.

Com objetivo de organizar nossos argumentos, este texto foi estruturado em cinco seções. Inicialmente, essa introdução que apresentou o problema, o objetivo e a pergunta que direcionou este estudo. Na segunda seção, situaremos os dois locus da pesquisa, também serão apresentados os procedimentos metodológicos. Na terceira seção, apresentaremos os pressupostos teóricos que fundamentam as análises dos dados coletados. Na quarta seção, o leitor terá acesso aos dados obtidos junto a professores da cidade de Cuiabá/MT e de Presidente Dutra/BA, bem como análises realizadas pelos pesquisadores. Na quinta e última seção, serão apresentadas as considerações finais.

\section{LOCUS DA PESQUISA E PROCEDIMENTOS METODOLÓGICOS}

A cidade de Cuiabá, capital do estado de Mato Grosso, foi criada oficialmente no dia 08 de abril de 1719, por Pascoal Moreira Cabral, completando 302 anos neste ano. Os primeiros registros indicam que, de 1673 e 1682, bandeirantes paulistas chegaram na região em busca da atividade garimpeira, fundando o primeiro povoado da região, no ponto onde o rio Coxipó deságua no rio Cuiabá, localidade que posteriormente foi batizada de São Gonçalo. Apesar das lutas, o município só foi elevado à condição de cidade por meio de uma Carta de Lei em 17 de setembro de 1818. Segundo dados atualizados do Instituto Brasileira de Geografia e Estatística (IBGE) $)^{1}$, Cuiabá tem 618.124 habitantes.

No âmbito educacional, a capital de Mato Grosso tem oferecido condições para as instituições de ensino públicas e privadas que ofertam desde a educação infantil ao nível superior, incluindo cursos de pós-graduação; na educação básica, houve a reformulação dos Documentos Normativos a partir da Base Nacional Comum Curricular aprovada por meio de resolução que alteraram o texto da Lei no 9.394/1996.

O outro locus da pesquisa é o município de Presidente Dutra, no interior do estado da Bahia, conhecida como a Capital Mundial da Pinha, devido à grande produção da fruta na cidade. Sua história remonta ao século XIX, por volta de 1884, com a chegada de um grupo de homens liderados por Antônio Baldoíno, Antônio Pereira Machado e Cazuza da Rocha,

\footnotetext{
${ }^{1}$ Dados retirados do site do IBGE referente ao ano de 2020. Disponível em: https://www.ibge.gov.br/cidadese-estados/mt/cuiaba.html Acesso em: 02 de fev. 2021.
} 
inspirados pela intenção de abrir uma nova rota que ligasse os povoados de Canabrava do Gonçalo e São Gabriel. Nessa empreitada, os membros da expedição encontram um terreno fértil com inúmeras lagoas, instalando-se na região e dando início ao que hoje é o município de Presidente Dutra.

Segundo dados do IBGE, o município tem $15.160^{2}$ habitantes, estando a $496 \mathrm{~km}$ da capital baiana, Salvador. No campo educacional, a cidade tem avançado na oferta da educação básica a todos os alunos, seja na área urbana ou rural, tendo apenas uma unidade escolar gerida pelo governo estadual que oferta o ensino médio - as demais escolas ofertam o ensino fundamental e são geridas pelo poder municipal.

Metodologicamente, a pesquisa se insere na abordagem qualitativa (MINAYO, 2007). Segundo a autora, essa abordagem é abrangente nas Ciências Sociais, pois tenta confrontar e/ou relacionar os dados de campo em sua amplitude, não se preocupando em definir uma única verdade, mas desvelar os processos sociais ainda poucos conhecidos. Ao final, essa abordagem visa proporcionar a construção e/ou revisão de novas formas de pensar e agir frente às problemáticas e fenômeno estudados.

Nessa frente, as informações até aqui tecidas permitem entender que a pesquisa com abordagem qualitativa é a mais adequada ao propósito deste estudo, uma vez que se busca identificar e analisar a importância das ações de formação inicial e continuada dos profissionais da educação sobre a educação inclusiva.

Originalmente, este trabalho integra uma pesquisa realizada no curso de Especialização em Docência com ênfase na educação inclusiva ofertado pelo Instituto Federal de Minas Gerais - Campus Avançado Arcos, no qual pesquisou-se a percepção de 74 professores atuantes na educação básica dos Municípios de Cuiabá/MT e Presidente Dutra/BA.

Para a coleta de dados, foi empregada a técnica de questionário online elaborado pela ferramenta Google Forms, oportunizando o acesso a vários profissionais, bem como abrindo espaço para que eles pudessem dar suas respostas com tranquilidade. Para tanto, elaboramos um questionário com 13 questões semiestruturadas com foco nos objetivos propostos. O cenário de pandemia provocado pela Covid-19 e o necessário distanciamento social foram fatores predominantes para a escolha do instrumento de coleta de dados.

\footnotetext{
${ }^{2}$ Dados retirados do site do IBGE. Disponível em: https://cidades.ibge.gov.br/brasil/ba/presidentedutra/panorama Acesso em 02/02/2021.
} 
As perguntas versaram sobre: (i) trajetória pessoal do respondente; (ii) trajetória escolar do respondente; (iii) trajetória profissional do respondente; (iv) suas experiências em relação a ações vivenciadas na formação inicial e continuada com foco na educação inclusiva; e (v) conhecimento e acesso às políticas públicas educacionais relacionadas à inclusão escolar em seu município. Importa salientar que a participação na pesquisa exigiu a leitura do Termo de Consentimento Livre e Esclarecido (TCLE) e, somente após concordância com o termo, o respondente teve acesso ao questionário. Guardados os princípios da ética na pesquisa, este estudo foi submetido à Plataforma Brasil e aprovado pelo Comitê de Ética em Pesquisa com Seres Humanos da Universidade Federal de Lavras (COEP/UFLA).

$\mathrm{Na}$ análise dos dados, buscamos empregar a técnica de análise de conteúdo proposta por Bardin (1979). A autora assevera a necessidade de organizar os dados em categorias conceituais de maneira a possibilitar uma interpretação que traga os significados que os próprios entrevistados atribuíram às suas experiências e suas vivências, demarcando como a inclusão escolar permeou sua formação inicial, e como a unidade escolar onde eles atuavam tem proposto essa discussão nos momentos formativos e práticos em sala de aula.

\section{A EDUCAÇÃo INCLUSIVA NO BRASIL: A NECESSÁRIA REFLEXÃo SOBRE POLÍTICAS PÚBLICAS DE FORMAÇÃO INICIAL E CONTINUADA}

A partir da Constituição Federal de 1988, observou-se mobilizações em busca da garantia do direito à educação a todos segmentos da população brasileira. Nesse sentido, foi preciso reestruturar as ações teóricas, práticas e curriculares para se pensar essa nova etapa da educação, agora numa perspectiva inclusiva e decolonial. Para Miranda (2013),

[...] processos decoloniais podem ser oportunidades de estabelecermos diálogos mais inter, menos hierárquicos nos projetos educativos, nas formas de pensarmos as políticas públicas [...] essa libertação tende de ameaçar as supremacias ideológicas, desestabilizando as tradições que permanecem na sociedade, "principalmente quando se persegue sentidos mais elásticos para o "pedagógico". (MIRANDA, 2013, p. 1072).

Era necessário pensar em novas pedagogias no chão da escola, uma vez que os espaços de formação inicial e continuada continuavam reproduzindo práticas hegemônicas e excludentes. Assim, por meio de lutas dos movimentos sociais e educacionais, a década de 1990 foi marcada por discussões para pensar a inclusão de pessoas com necessidades especiais na educação e os processos de inclusão escolar. Como citado anteriormente, a Lei nº 9394/1996 traz em seu bojo importantes discussões para pensar tais processos. 
Uma das conquistas dos movimentos sociais que lutavam pela educação foi a criação da Secretaria de Educação Continuada, Alfabetização, Diversidade e Inclusão (SECADI) em 2004, que teve um papel preponderante na política de inclusão, uma vez que esta instância governamental foi criada com desígnio de contribuir com as ações inclusivas que deveriam ser realizadas pelas instituições de ensino na busca pela valorização da diversidade e das diferenças existentes na sociedade que perpassam esses espaços (DINIZ, 2012). No entanto, após tantos anos de luta e de avanços na construção de políticas públicas para a inclusão, essa secretaria é extinta em 2019, após mudanças no MEC promovidas pelo Executivo Federal.

A partir da LDB de 1996, conforme artigo 62, as instituições de ensino superior deveriam ofertar uma formação docente que preparasse os acadêmicos para o exercício da docência e para o magistério na educação básica. No entanto, as condições dessa formação não ficam explícitas no documento, havendo a necessidade de outros documentos normativos capazes de organizar essa oferta. Assim, em $1^{\circ}$ de julho de 2015, o Conselho Pleno do Conselho Nacional de Educação (CNE/CP) normatizou a Resolução $\mathrm{n}^{\circ} 2$ que definiu as Diretrizes Curriculares Nacionais para a formação inicial em nível superior (cursos de licenciatura, cursos de formação pedagógica para graduados e cursos de segunda licenciatura) e para a formação continuada. Esse documento é tido por educadores e pesquisadores como um marco positivo na política pública de formação de professores no Brasil, pois, de fato, trouxe caminhos para pensar as estruturas curriculares e pedagógicas na formação de profissionais da educação. Segundo o documento, estas deveriam estar pautadas num processo dinâmico e complexo, com o olhar para formação integral do professor, contribuindo para melhoria da educação (BRASIL, 2015).

Sendo assim, a partir da Resolução CNE/CP nº 2/2015, as universidades públicas e privadas deveriam reestruturar os projetos pedagógicos dos seus cursos de licenciatura, ofertando uma formação inicial que atendesse, quanto aos princípios e caminhos a serem realizados, a realidade presente nas unidades de ensino do país durante essa Formação dos Profissionais para o Magistério da Educação Básica, conforme orienta o Artigo 3, inciso 5. Segundo o documento, essa formação deveria ser pautada

[...] como compromisso com projeto social, político e ético que contribua para a consolidação de uma nação soberana, democrática, justa, inclusiva e que promova a emancipação dos indivíduos e grupos sociais, atenta ao reconhecimento e à valorização da diversidade e, portanto, contrária a toda forma de discriminação (BRASIL, 2015, p. 4). (grifos nossos) 
Ou seja, é preciso pensar em processos educacionais que permitam ao futuro professor desconstruir os pré-conceitos existentes, reconhecer o espaço escolar como um grande campo da diversidade e representatividade social e, a partir de sua inserção nesse campo, já no estágio supervisionado, ser capaz de contribuir para uma educação mais humana e inclusiva. Para Diniz (2012), nesses espaços a inclusão deve ser encarada como um processo de mudança, de reestruturação da escola como um todo, visando assegurar que todos os estudantes possam ter acesso às oportunidades educacionais e sociais ofertadas pela escola, impedindo, assim, a segregação e o isolamento das pessoas com necessidades especiais. Segundo ele, "o princípio fundamental da educação inclusiva consiste em que todas as crianças devem aprender juntas, onde quer que isso seja possível, não importando quais dificuldades ou diferenças elas possam ter". (DINIZ, 2012, p.33).

Nesse mesmo caminho indicado por Diniz (2012), a Resolução CNE/CP n 2/2015 propõe um novo olhar para a Educação. No entanto, esse não deveria permanecer centralizado apenas na formação inicial, mas ocorrer diariamente nos processos de formação continuada, possibilitando ao docente um processo de formação emancipatório e permanente, com um olhar em sua práxis pedagógica, tendo condições de articular teoria, prática e realidade dos alunos, conduzindo-os “à consolidação da educação inclusiva através do respeito às diferenças, reconhecendo e valorizando a diversidade étnico-racial, de gênero, sexual, religiosa, de faixa geracional, entre outras. (BRASIL, 2015, p. 6).

No dia 27 de outubro de 2020, o CNE/CP homologou a Resolução nº ${ }^{\circ}$, que dispõe sobre as Diretrizes Curriculares Nacionais para a Formação Continuada de Professores da Educação Básica e instituiu a Base Nacional Comum para a Formação Continuada de Professores da Educação Básica (BNC-Formação Continuada).

A BNC-Formação Continuada propõe uma nova forma de pensar o papel do professor na atualidade, buscando fortalecer ações da prática docente, tornando o profissional protagonista de seu processo formativo, principalmente, a partir dos saberes adquiridos em sua trajetória, suscitando novas metodologias de ensino e processos de aprendizagem sintonizados às realidades socioculturais da esfera local e global da sociedade. Segundo o documento, o processo de formação continuada deve estar pautado em alguns fundamentos pedagógicos que permitam mudanças curriculares e práticas, dentro do sistema hegemônico, eurocêntrico e classificatório que tem definido o espaço escolar. Deve-se propor o

[...] desenvolvimento de capacidade gestora (gestão inclusiva e democrática) de equipes, instituições e redes de ensino, de forma a construir e consolidar uma cultura 
institucionalizada de sucesso e eficácia escolar para todos os alunos e membros das equipes, levando em consideração as características institucionais, as normativas, os costumes, o contexto sociocultural das instituições e das redes de ensino, bem como a sua clientela e o seu entorno. (BRASIL, 2020, p. 3).

A partir dessas estratégias, a Resolução CNE/CP n ${ }^{\circ}$ 1/2020 estipula que a realidade e os processos de inclusão educacional não seja algo complicado de acontecer, como a educação especial, por exemplo, mas um fator que seja efetivado nas instituições educacionais, mudando não apenas a formação inicial e continuada dos docentes, mas também as estruturas, os currículos, as práticas e o pensamento de cada agente envolvido no processo, permitindo, por meio da educação, a construção de uma sociedade livre, justa, democrática e inclusiva.

Apesar da Resolução supracitada na visão do Governo Federal trazer estratégias para organizar a formação continuada dos professores no Brasil, nota-se que a mesma não foi pensada em conjunto com as entidades representativas da educação, como a Associação Brasileira de Currículo (ABdC), a Associação Nacional de Pesquisa e Pós-graduação em Educação (Anped), Associação Nacional pela Formação dos Profissionais da Educação (Anfope) entre outras. Segundo um manifesto ${ }^{3}$ organizado por essas entidades em repúdio à homologação da Resolução CNE/CP n ${ }^{\circ}$, de 27/10/2020, a normativa seria um retrocesso na política de formação continuada dos professores. Segundo o texto, a nova resolução acentua os processos de desvalorização e precarização dessa etapa formativa, reforçando práticas impositivas e autoritárias do governo ao não ouvir as bases representativas tanto na revogação da Resolução CNE/CP n ${ }^{\circ}$ 2/2015 como nas discussões sobre a nova diretriz.

Segundo a nota de repúdio, a Resolução CNE/CP n $1 / 2020$ foi organizada para atender aos preceitos da Base Nacional Comum Curricular (BNCC), "direcionando a formação a um modelo de formação e profissionalização que tende a secundarizar o conhecimento teórico e sua mediação pedagógica na unidade teoria e prática” (p. 2). Mantendo-se essa concepção focada na pedagogia das competências, o conhecimento assume preponderância sobre a prática e, consequentemente, resulta no esvaziamento do processo de "formação intelectual e política dos professores, empobrecendo a formação e, consequentemente, a autonomia e o exercício do profissional" (idem). Assim, a luta das entidades reforça os ganhos alcançados pela Resolução $\mathrm{CNE} / \mathrm{CP} \mathrm{n}^{\circ} .2 / 2015$, tendo a formação inicial e continuada dos professores como um processo orgânico e articulado.

\footnotetext{
${ }^{3}$ Para ler o documento na íntegra, acesse http://www.abdcurriculo.com.br/post/manifesto-em-rep\%C3\%BAdio\%C3\%A0-homologa\%C3\%A7\%C3\%A3o-da-resolu\%C3\%A7\%C3\%A3o-cne-cp-n\%C2\%BA-1-de-27-10-2020que-define-as-diretrizes.
} 
Nesse sentido, diversas são as dificuldades enfrentadas pela Educação Especial e Inclusiva, principalmente no campo do ensino regular. Nesta perspectiva, é preciso confrontar práticas discriminatórias existentes no sistema de ensino. Desse modo, seria preciso

[...] entender como a formação inicial e continuada, destinada aos docentes que atuam dentro da educação básica nas áreas de Educação Especial e Inclusiva, vem ocorrendo ao longo das últimas décadas ganhando maior visibilidade dentro do cenário acadêmico e das políticas públicas e educacionais desenvolvidas no Brasil. (LEITE; MACHADO; SILVA; RIOS, 2019, p. 69).

O exercício de pensar a inclusão escolar apareceu em objeção à exclusão social a que estudantes com necessidades especiais foram submetidos, no próprio sistema regular de ensino brasileiro. Estes eram considerados indivíduos "incapazes", pois "até o final do século XVIII. a ignorância foi responsável pela rejeição desses indivíduos por parte da família, da escola e da sociedade, resultando na sua invisibilidade e internação em instituições que os percebiam como sujeitos anormais e incapazes do convívio social" (LEITE; MACHADO; SILVA; RIOS, 2019, p. 70). Ou seja, nessa perspectiva, as pessoas com necessidades especiais não tinham nenhuma utilidade para a sociedade.

Realizado pelo Instituto Nacional de Estudos e Pesquisas Educacionais Anísio Teixeira (INEP), o Censo Escolar de 2016 mostrou que cerca de 57,8\% das escolas brasileiras possuem alunos com algum tipo de deficiência em turmas regulares. Há 8 anos, esse percentual era de apenas 31\%. (BRASIL, 2017). De acordo com o Censo Escolar 2020, havia 1.308.900 matrículas na Educação Especial, sendo a maior quantidade concentrada no Ensino Fundamental (911.506 matrículas ou 69,64\%), considerando que a Educação Infantil responde por 8,46\% e o Ensino Médio Regular por 11,35\%; o restante das matrículas estão na Educação Profissional e Tecnológica e na Educação de Jovens e Adultos.

Segundo Duek (2014), "no Brasil, a discussão em torno da política educacional inclusiva começa a se delinear na década de 80, ganhando força nos anos 90, sob a influência de organismos internacionais e da publicação de diversos documentos e diretrizes" (p. 19). Procurando superar os paradigmas existentes na educação inclusiva e buscando consolidar a luta por uma educação verdadeiramente inclusiva, a Assembleia Geral da Organização das Nações Unidas (ONU), no dia 14 de outubro de 1992, instituiu o dia 3 de dezembro como o Dia Internacional da Pessoa com Deficiência.

Retomando os enunciados da Lei n 9.394/1996 em seu Capítulo V para a Educação Especial, Artigo 59, inciso III, determina-se que esses estudantes devem ter "professores com especialização adequada em nível médio ou superior, para atendimento especializado, bem 
como professores do ensino regular capacitados para a integração desses educandos nas classes comuns" (BRASIL, 1996, p. 24). Ou seja, está determinado que, na escola regular, havendo necessidade, será designado um atendimento de apoio especializado para atender às particularidades dos alunos. Para a LDB, o atendimento pode acontecer em escolas especializadas, mas isso somente quando não for possível sua integração a turmas comuns de ensino regular. Segundo os dados do Censo Escolar 2020, 88,08\% das matrículas informadas na modalidade Educação Especial estavam vinculadas a classes regulares e as demais 156.025 matrículas em classes especializadas.

Refletir sobre a formação dos professores atuantes no ensino regular que são responsáveis também por estudantes com necessidades especiais implica refletir acerca das tendências contemporâneas para a formação de todos os educadores da educação básica. Entendemos que no processo de inclusão escolar, é fundamental o uso da tecnologia assistiva, vista como "o conjunto de recursos e serviços que contribuem para proporcionar ou ampliar habilidades funcionais de pessoas com deficiência e, consequentemente, promover vida independente e inclusão" (DUEK, 2014, p. 23).

A formação de educadores para a educação especial e inclusiva exige a adoção de novos paradigmas. Tais professores devem ser capazes de renovar sua prática pedagógica, pois além de uma formação continuada e especializada serão capazes, junto da escola, de transformar a vidas de sujeitos que antes eram anulados e/ou esquecidos pela sociedade.

Um caminho possível para essa formação e construção da identidade profissional do educador é a formação continuada dos profissionais da educação em geral. É necessário que os profissionais estejam constantemente renovando suas práticas pedagógicas, indo além da simples aquisição e reprodução de conhecimentos, relacionando um conhecimento de vida adquirido na interação social. Contudo, esse exercício de Educação só será possível por meio do reconhecimento das crianças como sujeitos ativos da sociedade.

\section{A FORMAÇão INICIAL E CONTINUAdA dOS PROFESSORES COM FOCO NA INCLUSÃo eSCOLAR: O OLHAR dOS PROFESSORES De CuIABÁ/MT E PRESIDENTE DUTRA/BA}

Este estudo objetivou analisar a forma como a temática em tela tem sido desenvolvida nos cursos de formação continuada dos professores nas cidades Cuiabá, capital do estado de Mato Grosso, e Presidente Dutra, cidade do interior da Bahia. Igualmente, buscou-se identificar se em seus cursos de formação houve disciplinas preparatórias para os processos da educação inclusiva no cotidiano escolar de turmas da educação básica. 
Por meio do questionário eletrônico, os profissionais da educação dos municípios citados tiveram a oportunidade de contribuir com informações pessoais, profissionais e formativas relacionadas ao processo de inclusão escolar e como esta tem se apresentado em suas unidades de ensino. $\mathrm{O}$ formulário foi elaborado e disponibilizado aos participantes entre os dias 09 de setembro de 2020 a 15 de janeiro de 2021. Encerrado o período, buscamos organizar as informações que serão apresentadas nas análises.

O questionário contou com a participação de um total de 74 respondentes; destes, 75,7\% foram mulheres e $24,3 \%$ foram homens, ambos atuantes na educação básica dos respectivos municípios em turmas do ensino fundamental, majoritariamente. Interessa destacar que a maioria dos participantes $(32,4 \%)$ está na faixa etária de 45 a 55 anos de idade, seguido pelos professores com idade entre 25 e 35 anos (27,0\%). Em relação à continuidade na formação acadêmica, 77,0\% dos participantes possuíam formação a nível de pós-graduação, sendo a maioria desses cursos na modalidade Lato Sensu $(62,2 \%)$ e apenas um professor possuía titulação de doutorado.

Quanto ao tempo de atuação na docência, a maioria dos participantes $(40,2 \%)$ estava há mais de 20 anos trabalhando em instituições de ensino. Perguntados se tinham experiência na docência em turmas da Educação Básica, 93,2\% responderam afirmativamente, sendo que 41,2\% destes disseram ter mais de 20 anos de experiência nesta etapa da escolarização escolar, com passagem pelo ensino fundamental e ensino médio em instituições públicas ou particulares, realidade para muitos profissionais da educação no Brasil. Esse cenário de acúmulo de cargos reflete a desvalorização da carreira docente na maioria dos estados brasileiros e faz com que muitos tenham que complementar renda assumindo classes e/ou aulas em diversas instituições de ensino, acumulando, por consequência, dois ou três turnos de trabalho.

Embora a Lei $n^{\circ}$ 9.394/1996 estabeleça a formação em licenciatura plena como qualificação para o exercício de cargo ou função de Professor da Educação Básica, é importante salientarmos que, caso o curso de licenciatura não lhe ofereça formação para trabalhar os processos de inclusão dos estudantes com necessidades especiais, o profissional deve estar atento às possibilidades de formações específicas para a Educação Especial e Inclusiva, sendo essa ofertada prioritariamente oferecida pelos estabelecimentos e redes de ensino.

Assim, foi perguntado aos participantes: "você já participou de algum curso específico para trabalhar com a inclusão escolar de alunos com necessidades educacionais especiais (NEE)?”, sendo as opções: (i) Ainda não participei, apesar de já ter tido oportunidade; (ii) 
Ainda não participei, pois não me foi oferecida essa possibilidade pelo meu empregador; (iii) ainda não participei, mas já estou me organizando para pagar um curso nessa área; (iv) Já participei e o curso foi custeado pelo meu empregador; e $(v)$ Já participei, mas tive que arcar com as despesas do curso. As respostas foram organizadas no gráfico constante na Figura 1.

Figura 1 - Cursos realizados para trabalhar com alunos com NEE

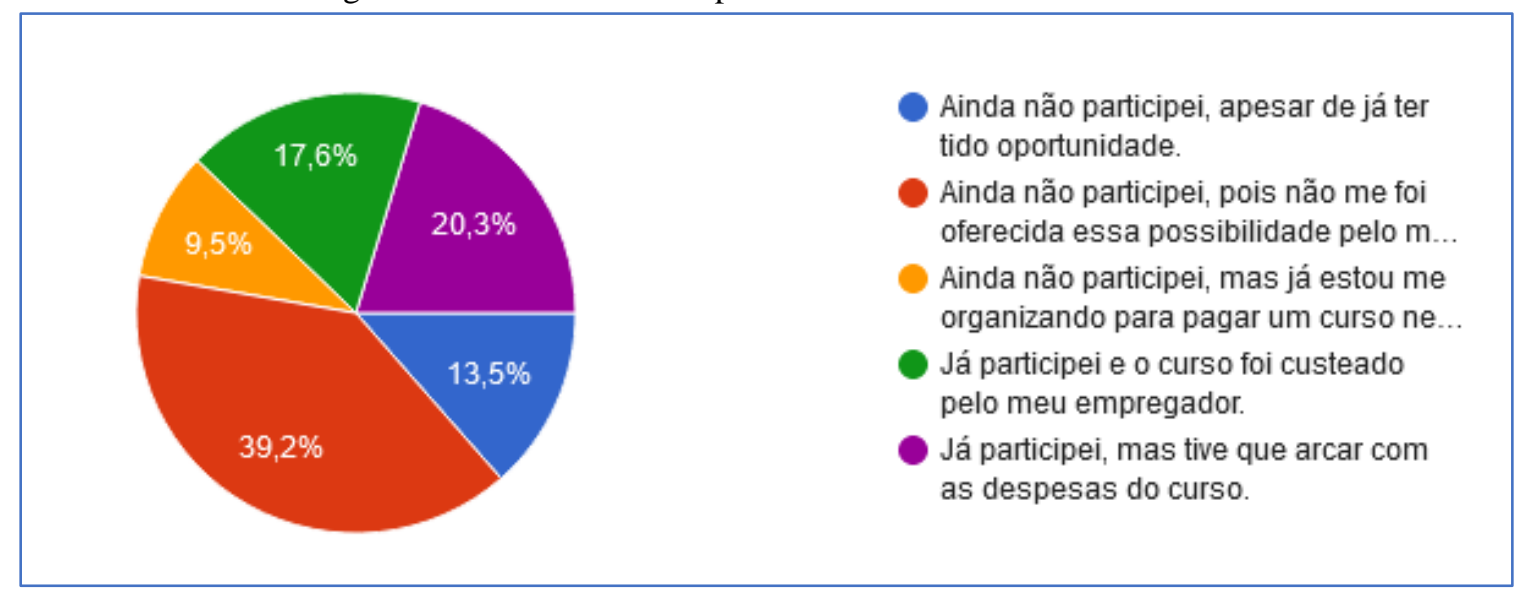

Fonte: Respostas dos participantes (2021).

Do universo de 74 professores entrevistados, 39,2\% (29 participantes) responderam que não realizaram nenhuma formação na área pela falta de oferta por parte do empregador. Outros 20,3\% (15 participantes) afirmaram que já realizaram formação sobre NEE, no entanto, tiveram que arcar com as despesas do curso, gerando déficit em seu orçamento no final do mês. Outros 13,5\% (10 participantes) reconheceram que já tiveram a oportunidade de participar da formação com foco na Educação Inclusiva, mas não aproveitaram a oportunidade. Outros 37,9\% (28 participantes) informaram que já participaram desse tipo de formação, todavia. Destes, 20,3\% tiveram a capacitação ofertada pelo empregador. Por fim, 9,5\% (7 participantes) disseram que ainda não haviam participado de nenhuma formação e que essa já estaria nos planos de formação que pretendiam realizar ao longo do ano.

Nesse sentido, tomando como premissa a importância de desenvolvimento de ações de formação continuada com foco na Educação Especial e Inclusiva, é preciso pensar em políticas públicas federais, estaduais e municipais de maneira a garantir a gratuidade destas ações para os profissionais da educação, especialmente aos professores - estas devem ser contínuas na rede pública, possibilitando que os profissionais estejam preparados e busquem informações teóricas e práticas para atender às necessidades educacionais dos alunos especiais. Assim, de maneira a termos um processo educativo verdadeiramente inclusivo, "é preciso repensar a formação de professores especializados, a fim de que estes sejam capazes de trabalhar em diferentes 
situações e possam assumir um papel-chave nos programas de necessidades educativas especiais" (UNESCO, 1994, p. 28). Esse processo de inclusão, de fato, perpassa a formação.

Dos 28 participantes que afirmaram já ter feito algum curso para trabalhar com a inclusão escolar de alunos com necessidades educacionais especiais (NEE), ou seja, que assinalaram as opções $(i v)$ e $(v)$ expostas na Figura 1, ao serem indagados se a formação realizada para o atendimento aos alunos com NEE contribuiu positivamente para o entendimento e mudanças das práticas sobre a educação inclusiva, 71,4\% (20 participantes) afirmaram que essa formação possibilitou repensar os conceitos que carregavam em relação à inclusão escolar. Segundo eles, a formação possibilitou mudanças positivas em suas práticas pedagógicas.

Os dados apontam para a importância da formação continuada na prática docente na mudança rumo a uma prática pedagógica significativa, afinal, como assevera Pletsch (2009, “a formação deve atender às necessidades e aos desafios da atualidade" e, para se alcançar este intento, sugere-se que "[...] o professor seja formado de maneira a saber mobilizar seus conhecimentos, articulando-os com suas competências mediante ação e reflexão teóricoprática" (p. 3). Ainda segundo a autora, esse deve ser o caminho para pensar de fato a efetivação da inclusão educacional nas unidades de ensino no país, ou seja, é preciso que ambas as partes cumpram o seu papel: o docente, ao contribuir, refletir e mudar suas práticas e os órgãos competentes ao gerenciarem o sistema de sua rede, devendo ofertar condições formativas, materiais pedagógicos e tempo para pensar os processos de inclusão.

Nesse viés, perguntamos aos professores se as escolas em que estavam atuando incentivavam a participação em cursos de formação específica para atuar com alunos com NEE. Como resposta, 59,9\% dos participantes (44 deles) afirmaram que a equipe gestora das suas unidades de ensino têm buscado dar suporte e incentivar a formação para, posteriormente, o professor ficar responsável por socializar os aprendizados alcançados com os demais profissionais da equipe.

Ampliando a discussão trazida por Diniz (2012), a construção de ações que valorizem os conhecimentos das comunidades escolares sobre o trabalho educacional com alunos especiais e que envolvam discussões com os professores locais é um processo de "aprender juntos", com seleção de oportunidades de formações que não impactem o orçamento dos profissionais e que resultarão em ganhos para toda a comunidade escolar. 
Ao analisar as questões relacionadas à formação e experiência dos professores que estão lidando com estudantes portadores de alguma NEE, percebe-se que apenas 37,9\% (28 participantes) possuem algum tipo de formação na área. Ademais, 62,2\% dos professores (46) não possuem experiência e/ou formação para educar esse tipo de aluno. É preciso ressaltar a importância de formar professores para trabalharem não apenas com alunos com NEE, mas também para atuarem em uma sociedade diversificada onde os indivíduos sejam compreendidos em seu contexto social considerando suas muitas limitações físicas e/ou psicológicas, conforme nos ensina Diniz (2012). No momento em que os pais procuram um atendimento apropriado e diferenciado voltado aos seus filhos com necessidades especiais, para lidar com cada especificidade, é de fundamental importância que as instituições de ensino elaborem um plano no qual seus educadores possuam uma formação específica em Educação Especial e Inclusiva ou que estejam renovando suas práticas por meio de uma formação continuada na área.

Apesar de a educação inclusiva ser um direito assegurado na Constituição Federal para todos, e sua efetivação deva ser realizada pelas redes de ensino contemplando suas necessidades, muitas unidades escolares não têm disponibilizado para os alunos que precisam um espaço específico de atendimento, como a sala de recursos multifuncionais (SRM), por exemplo, conforme demonstra o gráfico exposto na Figura 2.

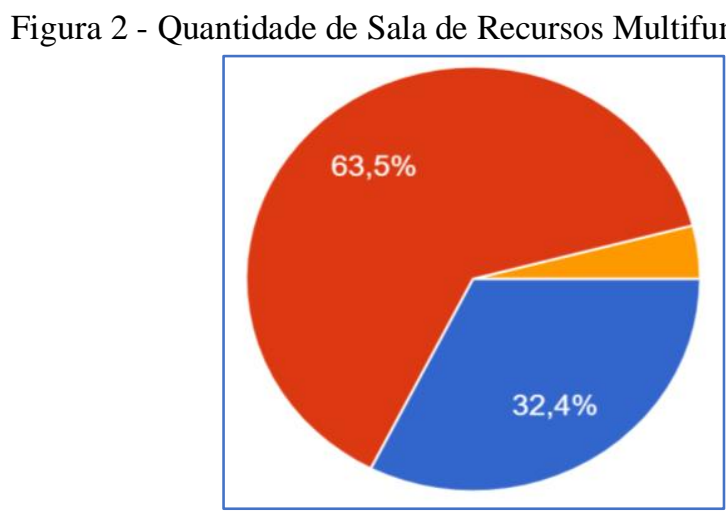

Fonte: Respostas dos participantes (2021).

Com base nas informações dos participantes, 63,5\% (47 deles) afirmaram que em sua unidade de lotação não existe SRM, 32,4\% (24 participantes) afirmaram que existe e 3 participantes não souberam informar. Apesar de ser uma política de inclusão implementada a partir da Política Nacional de Educação Especial na Perspectiva da Educação Inclusiva (MEC, 2008), muitas escolas não foram contempladas em sua totalidade com essa estrutura e, consequentemente, muitos profissionais tiveram que improvisar ambientes, buscar adquirir materiais com recursos próprios da escola de modo a possibilitar uma redução nos impactos 
educacionais dos alunos que precisam frequentar espaços de apoio pedagógico. Para Dutra e Griboski (2006), essa estrutura no espaço escolar se constitui

[...] como espaço de promoção da acessibilidade curricular aos alunos das classes comuns do ensino regular, onde se realizem atividades da parte diversificadas, como o uso e ensino de códigos, linguagens, tecnologias e outros complementares à escolarização, visando eliminar barreiras pedagógicas, físicas e de comunicação nas escolas. (DUTRA; GRIBOSKI, 2006, p. 19).

Ainda foram apontadas outras dificuldades para o desenvolvimento das práticas que, nas sem, têm permeado os espaços educacionais de alguns entrevistados, conforme narrativas apresentadas pelos participantes nos questionários:

[...] O atendimento na sala acontece no contraturno. A professora de sala passa os relatórios semanais para que se possa planejar as atividades, obviamente usando os recursos pedagógicos disponíveis.

[...] A sala se encontra instalada, porém não funciona.

[...] Sim, é trabalhado com o aluno no contraturno só que a professora não tem a formação adequada. (Excertos retirados de questão subjetiva presente no questionário eletrônico, 2021).

Diante dos relatos, podemos supor que persiste um distanciamento entre os documentos norteadores e as realidades do cotidiano escolar em relação a essa utilização das salas de recursos que visam prestar um atendimento especializado aos estudantes com necessidades educacionais especiais, corroborando com os estudos de Pletsch (2009). De fato, é preciso denunciar o descaso do poder público em relação a esse atendimento, ainda somado à falta de contratação de profissionais especializados para o atender os alunos com NEE. Sendo uma realidade que muitas escolas não têm profissionais efetivos específicos para atendimento aos alunos com NEE, a falta de contratação resultará, inevitavelmente, no fechamento da SEM ou em adaptações feitas pela equipe pedagógica de maneira a oferecer um atendimento mínimo àqueles alunos. Assim, apesar de existir uma política nacional que regulamenta tal estratégia de ensino inclusiva, esta não tem sido uma realidade nos cotidianos das escolas, de acordo com os dados coletados neste estudo. Os dados da pesquisa reforçam os ainda presentes processos de exclusão no cotidiano escolar. Segundo Dutra (2010, p. 3), esse “[...] programa de implantação de Salas de Recursos Multifuncionais constitui uma medida estruturante para a consolidação de um sistema educacional inclusivo [...]". Outra questão importante é o investimento que deve ser feito na equipagem desses ambientes, especialmente com recursos de tecnologia assistiva, conforme aponta Duek (2014).

A partir das informações relacionadas ao atendimento dos alunos com NEE, buscamos conhecer o processo de formação continuada dos professores na área da Educação Especial e 
Inclusiva, e como esta tem se delineado no espaço educacional. Nessa perspectiva, $52,7 \%$ dos professores (39 participantes) não conhecem os documentos oficiais que regulamentam a educação especial na escola onde trabalham, sobretudo, as ações inseridas no Projeto Político Pedagógico (PPP), o qual deveria ser elaborado com a participação de todos os segmentos da comunidade escolar. Tal documento desenha-se como a sistematização de um planejamento participativo, definindo as ações educativas que serão norteadas durante o processo educacional da unidade de ensino, propondo um caminhar pedagógico e formativo aos profissionais (VASCONCELLOS, 2005) pois, se a escola se propõe a ser para todos e todas, é importante que as estratégias para atendimento aos alunos com NEE estejam documentadas no PPP.

Já 47,3\% dos professores afirmaram conhecer alguns ou todos os documentos que normatizam a educação especial e inclusiva no espaço escolar. Ao ser pedido para que se listassem os documentos que conheciam, eles citaram a Declaração de Salamanca, a Política Nacional de Educação Especial na Perspectiva da Educação Inclusiva, o Estatuto da Criança e do Adolescente (ECA), a Lei de Diretrizes e Bases da Educação Nacional (LDB), bem como o Projeto Político Pedagógico.

Quanto à formação continuada, 64,9\% dos professores (48 participantes) afirmaram que essa seria de suma importância para as atividades desenvolvidas com os alunos com NEE, contribuindo não apenas para mudança das práticas pedagógicas, mas também para as práticas de vida. Assim, para que se tenha um ensino de qualidade, faz-se necessário um corpo docente preparado qualitativamente ao exercício de suas funções, que tenha uma remuneração justa por seu trabalho já que a formação docente resultada das escolhas pessoais, das possibilidades, das decisões do empregador (público/privado) e do encontro do profissional com os desafios que o trabalho cotidiano escolar lhe traz (LEITE; MACHADO; SILVA; RIOS, 2019, p. 73).

\section{CONSIDERAÇões FinAIS}

Este estudo objetivou entender como acontece a formação dos educadores nos cursos de formação inicial e continuada com relação à educação inclusiva e se a prática torna-se real no exercício da docência em duas cidades brasileiras, Cuiabá no estado de Mato Grosso e Presidente Dutra, na Bahia.

Os dados coletados neste estudo contribuíram para o entendimento de como ocorrem os processos de ensino para os alunos com NEE no Brasil atual. Eles nos mostram diversos aspectos relacionados à prática de ensino na educação básica e, também, os desafios da formação do professor para trabalhar a inclusão escolar no cotidiano das escolas. Dessa forma, 
esses dados apontam para um necessário investimento na formação continuada dos professores que já exercem a docência e na reformulação dos projetos pedagógicos dos cursos de licenciaturas de maneira a formar professores atentos para a questão da inclusão. Com essas ações, os professores terão maior possibilidade para mobilizar seus conhecimentos, articulandoos com suas competências mediante ação e reflexão teórico-prática, como nos ensina Pletsch (2009).

Apesar de a nossa Constituição Federal de 1988 definir, em seu Art. 205, a educação como um direito de todos os cidadãos, os professores participantes dessa pesquisa indicaram que as tentativas de colocar em sala de aula estudantes com NEE têm sido feitas por meio de programas fragmentados e professores ainda não formados.

Por fim, entendemos que este estudo, ao dar voz aos professores, possibilitou a compreensão da necessidade de ampliar esforços na formação continuada com foco na educação especial e inclusiva. Por isso, há a necessidade de uma formação contínua do educador para esta modalidade de ensino e a capacidade de reflexão em relação à função pedagógica do professor como sujeito formador no tecido social. Somente dessa forma os envolvidos no sistema educacional promoverão uma mudança no pensamento da sociedade e, sobretudo, no caráter participativo e motivador da escola - através de impulso democrático que leva a uma reflexão coletiva.

\section{REFERÊNCIAS}

BARDIN, Laurence . Análise de Conteúdo. Lisboa: Editora 70, 1979.

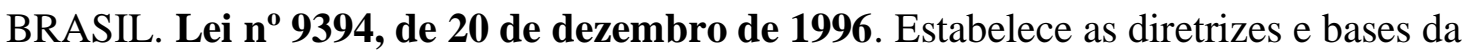
educação Nacional. Diário Oficial da União, Brasília, DF, 23 dez. 1996.

BRASIL. Ministério da Educação, Secretaria de Educação Especial. Projeto Escola Viva: Garantindo o acesso e permanência de todos os alunos na escola - Alunos com necessidades educacionais especiais, Brasília: MEC/SEESP, 2000, vol. 6.

BRASIL. Presidência da República. Lei n.10.172, de 9 de janeiro de 2001. Aprova o Plano Nacional de Educação e dá outras providências. Disponível em: http://www.planalto.gov.br/ccivil_03/leis/leis_2001/110172.htm . Acesso em: 5 fev. 2021.

BRASIL. Resolução CNE/CP 1/2002, de 18 de fevereiro de 2002. Institui as Diretrizes Curriculares Nacionais para a formação de professores da educação básica, em nível superior, curso de licenciatura, de graduação plena. Documento aprovado em 18.02.2002, publicado no DOU em 09.04.2002. 2002a. Disponível em: http://portal.mec.gov.br/index.php?option=com_docman\&view=download\&alias=159261 rcp001-02\&category slug=outubro-2020-pdf\&Itemid=30192 . Acesso em: 22 fev. 2021. 
BRASIL. Constituição da República Federativa do Brasil: promulgada em 5 de outubro de 1988. 4. ed. São Paulo: Saraiva, 1990.

BRASIL. Conselho Nacional de Educação. Resolução CNE/CP nº 02/2015, de $1^{\circ}$ de julho de 2015. Define as Diretrizes Curriculares Nacionais para a formação inicial em nível superior (cursos de licenciatura, cursos de formação pedagógica para graduados e cursos de segunda licenciatura) e para a formação continuada. Brasília, Diário Oficial [da] República Federativa do Brasil, seção 1, n. 124, p. 8-12, 02 de julho de 2015a. Disponível em:

http://portal.mec.gov.br/docman/agosto-2017-pdf/70431-res-cne-cp-002-03072015-pdf/file . Acesso em: 10 fev. 2021.

BRASIL. Conselho Nacional de Educação. Resolução CNE/CP nº 1, de 27 de outubro de 2020. Dispõe sobre as Diretrizes Curriculares Nacionais para a Formação Continuada de Professores da Educação Básica e institui a Base Nacional Comum para a Formação Continuada de Professores da Educação Básica (BNC-Formação Continuada), Brasília - DF, 2020. Disponível em: https://www.in.gov.br/en/web/dou/-/resolucao-cne/cp-n-1-de-27-deoutubro-de-2020-285609724 Acesso em: 10 fev. 2021.

BRASIL. Inep, Instituto Nacional de Estudos e Pesquisas Educacionais Anísio Teixeira. 2016. Disponível em: http://portal.mec.gov.br/docman/fevereiro-2017-pdf/59931-app-censoescolar-da-educacao-basica-2016-pdf-1/file. Acesso em: 10 de mar. de 2021.

BRASIL. Política Nacional de Educação Especial na Perspectiva da Educação Inclusiva. Brasília: MEC/SEESP, 2008. BRASIL. Decreto nº 6.949 de 25 de agosto de 2009.

DINIZ, Margareth. Inclusão de pessoas com deficiência e/ou necessidades específicas: avanços e desafios. Belo Horizonte: Autêntica, 2012.

DUEK, Viviane Preichardt. Formação Continuada: análise dos recursos e estratégias de ensino para a educação inclusiva sob a ótica docente. Educ. rev., Belo Horizonte, v. 30, n. 2, p. 17- 42, Junho, 2014. Disponível

em:https://www.scielo.br/scielo.php?script=sci_arttext\&pid=S0102-

$46982014000200002 \& \operatorname{lng}=e n \& n r m=i s o$. Acesso em: 11 de mar. de 2021.

DUTRA, Claudia Pereira. Manual de Orientação: Programa de implantação de sala de recursos multifuncionais. Brasília: MEC/SEESP, 2010.

DUTRA, Claudia Pereira; GRIBOSKI; Claudia Maffini. Educação Inclusiva: um projeto coletivo de transformação do sistema educacional. In: Ministério da Educação. Ensaios

Pedagógicos-III seminário nacional de formação de gestores e educadores. Brasília: Ministério da Educação/Secretaria da EducaçãoEspecial,2006. p. 17-23.

LEITE, Kátia Cristina; MACHADO, Maikson Damasceno; SILVA; Eliata; RIOS, Jane Adriana Vasconcelos Pacheco. Memórias da formação de professores em educação especial no município de Jacobina. Inclusão e educação 3. 3ed.: Antonella Carvalho de Oliveira, 2019, p. 69-79. Disponível em: https://www.atenaeditora.com.br/wpcontent/uploads/2019/01/E-book-Inclus\%C3\%A3o-e-Educa\%C3\%A7\%C3\%A3o-3.pdf Acesso em: 20 de mar. 2021. 
LOURO, Guacira Lopes. Gênero, sexualidade e Educação: uma perspectiva pós estruturalista. São Paulo: Vozes, 1997.

MINAYO, Maria Cecília de Souza. Pesquisa social: teoria, método e criatividade. Petrópolis: Vozes, 2007.

MIRANDA, Claudia. Apresentação. In: WALSH, Catherine (Org.). Pedagogías Decoloniales: prácticas insurgentes de resistir, (re) existir y (re) vivir. 1. ed. Equador: Abya Yala, 2013, v. 1, p. 15-18.

PLETSCH, Márcia Denise. A formação de professores para a educação inclusiva: legislação, diretrizes políticas e resultados de pesquisas. Educ. rev., Curitiba, n. 33, p. 143-156, 2009.Disponível em:http://www.scielo.br/scielo.php?script=sci_arttext\&pid=S010440602009000100010\&lng=en\&nrm=iso. Acesso em: 07 Mar. 2021. http://dx.doi.org/10.1590/S0104-40602009000100010.

PNAD Educação 2019: Mais da metade das pessoas de 25 anos ou mais não completaram o ensino médio. Agência IBGE Notícias, 16 de julho de 2020. Disponível em: https://agenciadenoticias.ibge.gov.br/agencia-sala-de-imprensa/2013-agencia-denoticias/releases/28285-pnad-educacao-2019-mais-da-metade-das-pessoas-de-25-anos-oumais-nao-completaram-o-ensino-medio. Acesso em 7 abr. 2021.

UNESCO. Declaração de Salamanca: Sobre Princípios, Políticas e Práticas na Área das Necessidades Educativas Especiais. Salamanca/Espanha, 1994. Disponível em: http://portal.mec.gov.br/seesp/arquivos/pdf/salamanca.pdf . Acesso em: 27 jan. 2021.

VASCONCELLOS, Celso dos Santos. Planejamento- Projeto de ensino-aprendizagem e projeto político pedagógico. 14. ed. São Paulo: Libertad, 2005. 